\section{The influence of customer value on word of mouth: a study of the financial services company in Brazil}

\author{
Sandro Bonfim da Costa \\ Insper, Marketing Department, São Paulo, Brazil \\ Danny Pimentel Claro \\ Insper, Marketing Department, São Paulo, Brazil
}

Adriana Bruscato Bortoluzzo

Insper, Quantitative Methods Department, São Paulo, Brazil
Received on

03/06/2017

Approved on

09/05/2017

Responsible editor:

Prof. Dr. Susana Costa e Silva

Evaluation process:

Double Blind Review

\begin{abstract}
Purpose - Our study analyzes the non-linear effect of customer lifetime value (CLV), which accounts for the revenue accumulated over the lifetime of a customer relationship, calculated using a discount rate, on customer referral value (CRV), which accounts for the value created by customers converted to the firm.
\end{abstract}

Design/methodology/approach - We collected data from customers of a financial institution that provides retirement plan products. A random sample of 768 customers provided the full names of individuals to whom they made a recommendation. After these names were elicited, respondents and referrals were identified in the firm's records, and we calculated the CLV and CRV values.

Findings - The results show the existence of a U-shaped effect of CLV on CRV, and a negative linear effect of CLV on recommendation intention.

Originality/value - Our study contributes to the body of literature on word of mouth by focusing on a product and business segment with low perceived brand differentiation and low customer involvement. We contribute to the marketing literature by showing a U-shape relationship between CLV and word of mouth activity, represented by CRV.

Keywords - Word of mouth; Relationship; Recommendation; Customer performance.

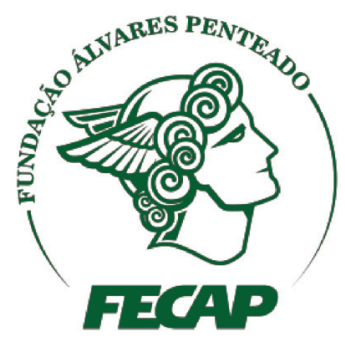

Review of Business Management

DOI: $10.7819 /$ rbgn.v20i2.3798 


\section{Introduction}

Previous research has found evidence suggesting that relationship marketing is a successful strategy for firms. Relationship marketing encompasses marketing activities to establish, develop, and maintain successful exchange relationships with customers (Palmatier, Dant, Grewal, \& Evans, 2006). A solid and longterm relationship with customers improves loyalty and enhances retention (Kumar \& Reinartz, 2016). Moreover, firms create a competitive advantage by leveraging their marketing activities to convert customers into relationship marketingbased assets (Chang \& Olumide, 2016). As a result, the marketing relationship generates positive word of mouth, in which customers play the role of referring other potential customers to a company.

Any individual in the firm can play the customer referral role and boost word of mouth to promote and share experiences. The classic Westbrook (1987) study defined word of mouth as any informal communication directed at other customers about the use and features of products and services, and about their vendors. Word of mouth affects most purchasing decisions and has been the focus of more and more research in recent years. Consumers rely on referrals and lessons from other consumers' comments when making a purchase decision (Berger, Jonah, \& Schwartz, 2011). Word of mouth is even stronger where there is more intense exchange through digital channels, such as the internet and social media. Efforts by firms include intensifying campaigns in digital channels to influence and monitor word of mouth activity (Kozinets, Valck, Wojnicki, \& Wilner, 2010). In addition, maintaining word of mouth depends less on how interesting the products are and more on how accessible they are in the consumer's mind (Kumar, Petersen, \& Leone, 2010).

There is a need to study word of mouth activity, what drives word of mouth, and its impact on performance. Kumar, Petersen, and Leone (2010) point out that the financial value of word of mouth must be large, but it is complex to measure. Capturing word of mouth and performance for each customer becomes even more relevant in the context of competitive pressure and increasing costs of delivering value to customers. The valuable information about customers' word of mouth activities and performance enables firms to better understand every individual customer and develop proper marketing activities for every opportunity in the customer portfolio. Acting assertively on the best customers is key, and this is at the heart of the marketing research agenda suggested by Kumar, Reinartz, and Werner (2016).

Our study aims to analyze the impact at the individual customer level of customer lifetime value (CLV), which accounts for the revenue accumulated over the lifetime of a customer relationship, calculated using a discount rate, on customer referral value (CRV), which accounts for the value created by customers converted to the firm. First, we deepen the understanding of the impact of customer performance on effective recommendations created by word of mouth. Second, we analyze the effect of CLV on recommendation intention, measured by a 1-10 recommendation score. Third, we run a cluster analysis to identify customer segments according to their performance and effective recommendation value, which enables us to profile customers as brand promoters accounting for their current and potential value for the firm. The contribution of our study lies in developing and empirically testing two key constructs for marketing, adding to the little relationship marketing research that exists in the field.

The first construct is CRV, which captures the financial result driven by word of mouth and follows previous research (Kumar et al., 2010). CRV is composed of the value derived from customers' recommendations that result in new customer purchases. CRV is the sum of the revenue derived from all the individuals recommended by an existing customer. The few existing studies that have measured CRV sought 
to identify customer referral value based solely on recommendation history (Kumar, Petersen, \& Leone, 2007). In our study, we capture the construct by assessing effective recommendations that have been made up to a certain point in time, thus representing in real form the value created by customer recommendations. Our construct pinpoints the names referred and assures that these are crosschecked with the firm database to calculate the CLV of the converted customers. It is important to point out the difficulty of obtaining such effective recommendation data because it is necessary to carefully scrutinize names of referred individuals.

The second construct is CLV. Taking into consideration the history and future revenue potential of each customer, CLV enables a customer's value to a firm during the active time of the relationship to be estimated, including the value created in past purchases. Previous research has shown the importance of CLV (Venkatesan \& Kumar, 2004; Kumar, Reinartz, \& Werner, 2016) and suggested accounting for the value of the entire flow of customer purchases throughout the lifetime of a customer's relationship with the company. It also accounts for the present value of future customer cash flow (Pfeifer, Haskins, $\&$ Conroy, 2005) or the sum of the discounted cash flow generated by any customer during that customer's relationship with the firm (Berger $\&$ Nasr, 1998). Moreover, CLV accounts for the future by incorporating the dynamic nature of customer behavior and enabling firms to treat customers individually depending on their value contribution to the firm (Kotler \& Armstrong, 2016). In addition to measuring individual customer value, this construct for converted customers is the key input for calculating CRV.

Since acquiring new customers is more expensive than retaining current ones, measuring and leveraging CLV is a top priority. This has helped firms identify the most profitable customers and engage in marketing activities for relationship management in recent years (Chang \& Olumide, 2016). Moreover, to maximize a firm's profitability, it is a critical to manage customers by jointly assessing customer value and customer referral activity (Kumar et al., 2010). This full analysis provides a complete view of each customer's value by encompassing the revenue generated by them as well as their behavior in terms of spreading the word about brands, products, and services. So, our study sought to examine the relationship between CRV and CLV, and this model can change the way the value of each customer is evaluated by firms. Kumar et al. (2007) suggested that the relationship between these two metrics may be non-linear, identifying customer profiles with low CLV and high CRV and customers with high CLV and low CRV.

To study the impact of CLV on CRV, we collected data from customers of a financial institution that provides retirement plan products. In spite of industry growth, the banking industry is hardly perceived as "something to rely on", and investors experience difficulties in handling their investments for the long term future. A random sample of 768 customers was used to test the hypotheses of our theoretical model. Respondents were asked to communicate their willingness to recommend (ranging from 0 to 10) and the full names of the individuals to whom they made a recommendation. After the referred names were elicited, the respondents and referrals were identified in the firm's records, and we calculated the CLV and CRV values. The firm also provided demographic and consumer behavior data used as controls.

\section{Customer Referral and Value}

Previous research has investigated CLV as a powerful performance outcome of marketing actions. However, few studies have advanced on concepts related to customer referral and the practical use in companies (see Table 1). Relationship marketing literature proposes that relationship marketing success results in word of mouth in which the firm ends up being referred to potential customers (Palmatier et al., 2006). The classic work of Brooks (1957) and Dichter 
(1966) about the word of mouth process proposes that customers are effective and reliable sources of information affecting most purchasing decisions. Interpersonal communication plays an important role in any individual's choices (Katz \& Lazarsfeld, 1955). Some factors may even increase the relevance of these communications in the context of consumption. For instance, increasingly intense interaction between people, whether at work, in school, or even in online social networks, is conducive to the intense dissemination of information on products and services. The dissemination may take place actively, through the direct presentation of product characteristics and opinions, and passively, as visual dissemination through photographs.

Word of mouth occurs in situations where the consumer searches for information about a product he or she intends to purchase or when he or she receives feedback and information from someone else who has purchased it. When purchasing services, consumers tend to rely even more on the indications of other people, since services are intangible and experiential. Thus, before buying, consumers use references such as price, physical evidence (e.g., appearance), firm image, and references received from people close to them, such as friends and relatives (Zeithaml, Berry, \& Parasuraman, 1993). When customer satisfaction levels are high, word of mouth activity is more likely, since a more satisfying situation activates an enchantment effect and less satisfaction can trigger regret (Steiner, Schlemer, \& Padua, 2005). It is expected that satisfaction for a particular product leads to repeat buying behavior, positive word of mouth, and greater tolerance in the case of problems with the product. 


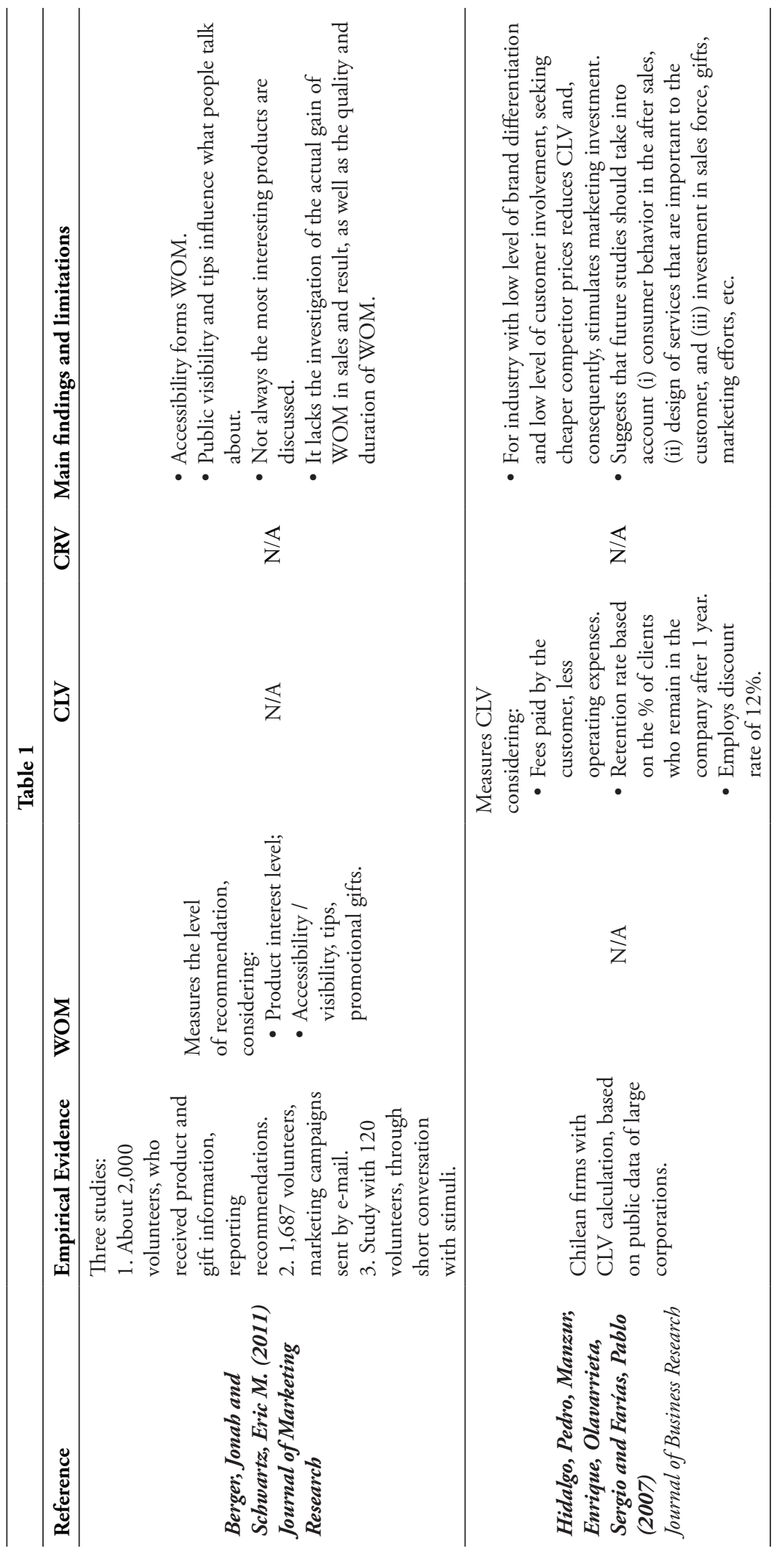




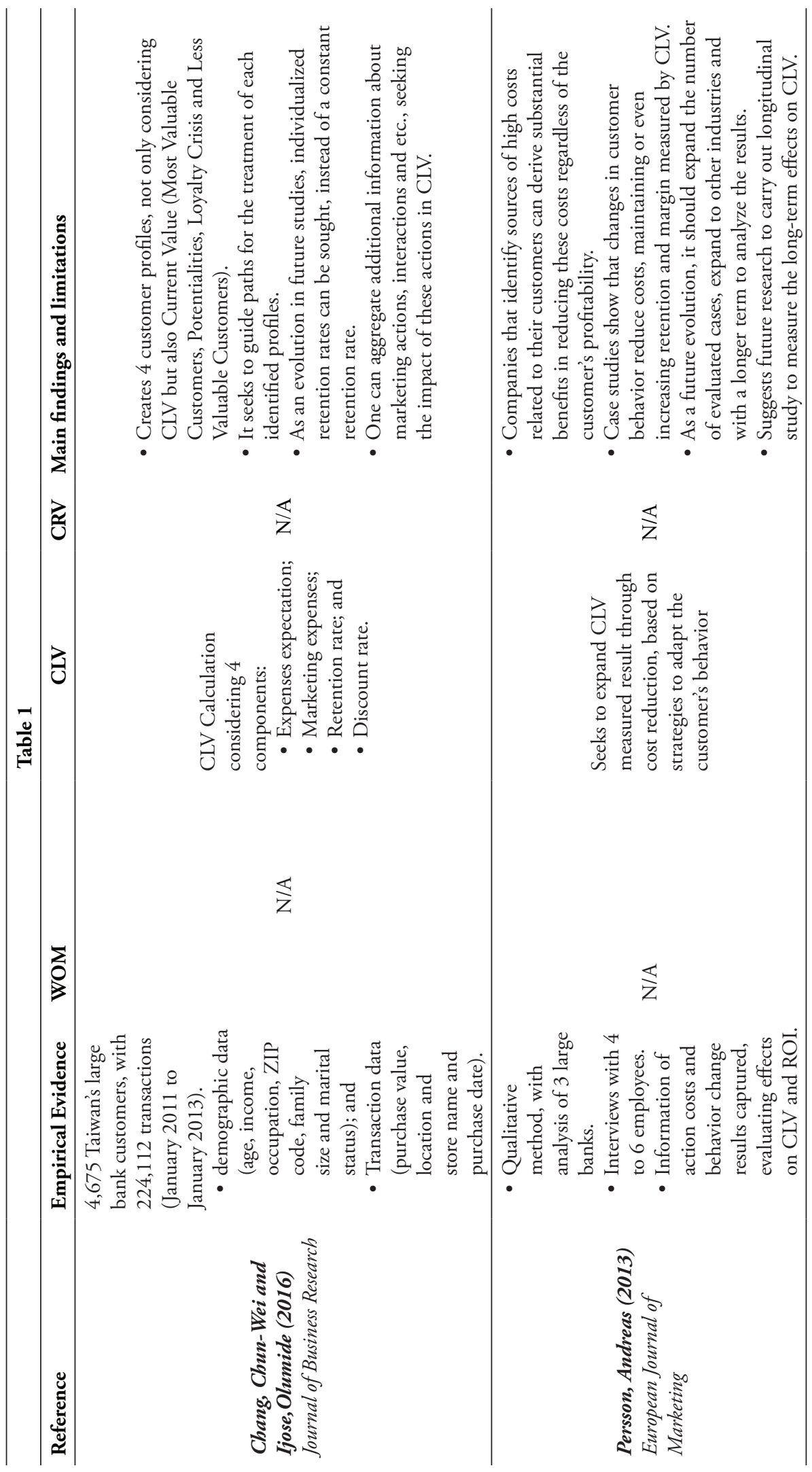




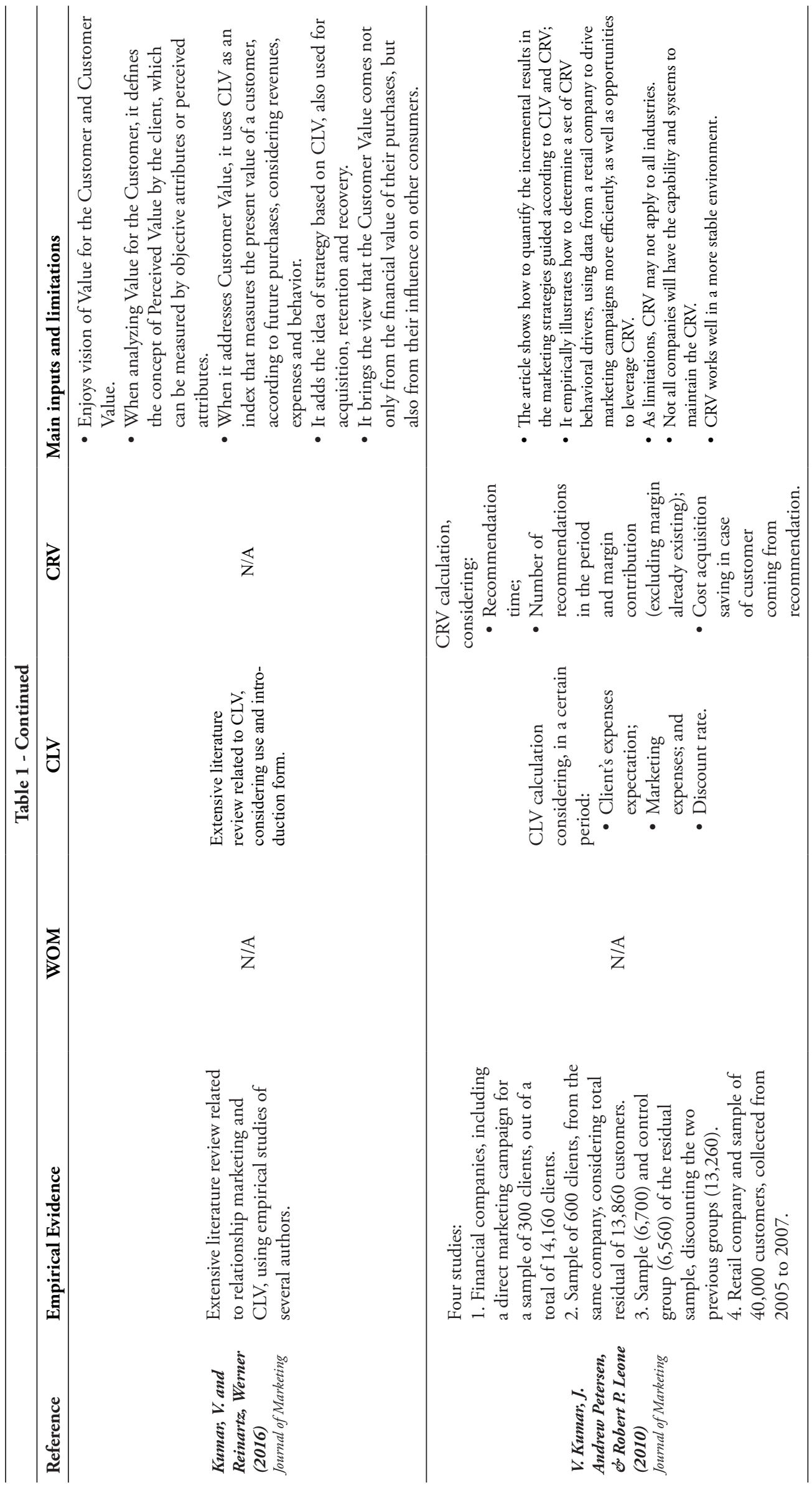


The influence of customer value on word of mouth: a study of the financial services company in Brazil

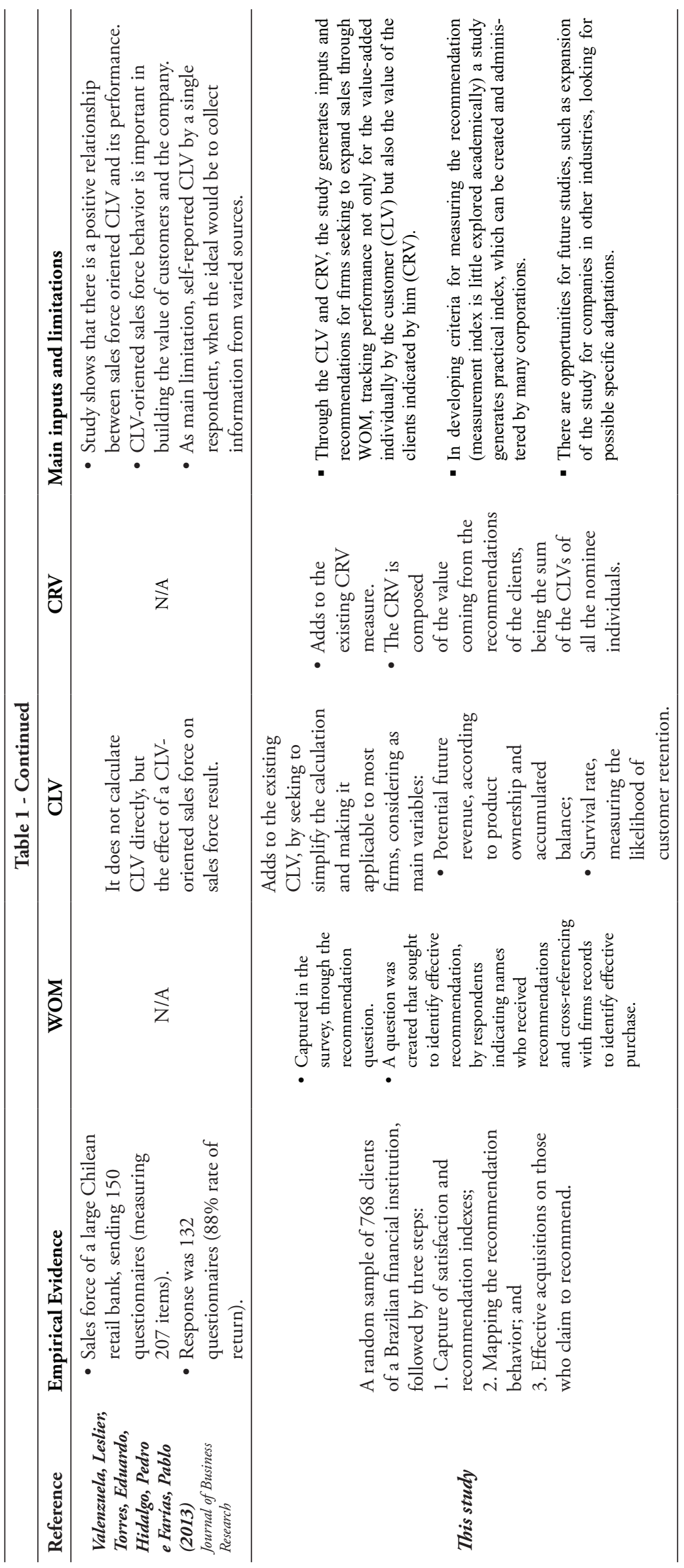


Word of mouth relates to attitudinal and behavioral dimensions of loyalty. It involves a customer positively recommending a service or product to another potential customer. In addition, some results show that word of mouth may be the best way to monitor high levels of loyalty (Reichheld, 2003). Loyal customers, who have a strong relationship with a firm, brand, product, and/or vendor, are willing to risk their reputation by recommending it to someone else. Loyalty precedes word of mouth, based on the logic that loyal customers: (i) make firm, positive recommendations to others in their reference group (friends and relatives); (ii) are more motivated to process new information about the firm (to take notice of innovations, for example); and (iii) are more resistant to being persuaded by information that goes against their attitudes (Dick $\&$ Basu, 1994). The referral component of word of mouth includes the time when a customer enters into a transaction with a firm and passes his or her purchase experience and motivation on to another customer. Studies have shown that customers who have received a referral and purchased products and/or services have proven to be more profitable over time (Kumar et al., 2010).The decision whether or not to recommend a firm depends on the individual's perception of the cost and benefit of such an exchange (Ryu \& Feick, 2007). As a result, using only willingness to recommend leads to inconsistency because willingness does not fully conceptualize referral activity (Kumar et al., 2010). There are three drivers of referral: (i) postpurchase anxiety reduction, (ii) impact on other people's impressions, and (iii) a real concern for others and thus helping in their decision process (Ryu \& Feick, 2007). There are costs when recommending, such as effort cost and time spent on communication. There is also the risk that the recommendation wears out the relationship, if the product is not considered appropriate.

Firms influence word of mouth intentionally through consumer-to-consumer communication using specific campaigns called Word of Mouth Marketing (Kozinets et al., 2010).
Specific campaigns increase word of mouth and referrals, intensified with increasing use of the internet and thus gaining even more strength and reach (Kozinets et al., 2010). Decisions about how much money to spend on each marketing effort are particularly important. Consequently, in marketing communication, there is a need to develop models that focus on maximizing CRV rather than just measuring CLV (Hidalgo, Manzur, Olavarrieta, \& Farías, 2008).

CRV is a key construct of the marketing relationship, especially because the traditional consumer satisfaction construct is not so useful. Previous research studied two years of questionnaire responses, actual consumer behavior (buying and referral patterns), and revenue growth, and found that the growth driver was not consumer satisfaction or loyalty, but actually the predisposition to recommend the product or service to someone else (Reichheld, 2003). There was no direct relationship between satisfaction, consumer behavior, and growth. The construct that proved to be the best growth predictor was "How likely is it that you would recommend this particular brand/product/service to a friend or colleague?" In several industries, there is a strong correlation between firm growth and the percentage of customers who are "promoters", i.e. those who responded very highly on the recommendation scale (Reichheld, 2003). This shows the importance of assessing CRV as a key construct of the marketing relationship.

CLV allows us to estimate customers' present and future value to a firm considering their history and purchase-making potential. Based on Venkatesan and Kumar (2004), CLV considers each customer's future revenue potential according to product ownership and the cumulative product purchase balance. In this way, it is possible to incorporate all the value generated by a customer through past purchases. CLV also considers a customer's survival rate, which measures the probability of each customer staying in the long term. The inclusion of the survival component aims at adding to the construct a way of measuring 
the strength of each customer's relationship with the firm. This component enables this strength to be monitored, as developing and maintaining long term relationships with customers is at the heart of relationship marketing (Berger \& Nars, 1998).

Previous studies show that correctly allocating marketing resources to maximize CLV leads to effective results in firm financial performance. In addition, CLV has gained acceptance as a measure of the obtainment, growth, and retention of the right customers through customer relationship management (Boulding, Staelin, Ehret, \& Johnston, 2005). Researchers suggests that CLV is a good way of selecting customers and designing marketing programs because customers selected for marketing actions through the CLV model can add more value than the ones selected by traditional relationship measures (Reinartz \& Kumar, 2003).

CLV includes purchase frequency, contribution margin, and marketing costs as a function of the future contribution margin, the customer's propensity to continue the relationship (retention), and the marketing resources allocated to the customer (Venkatesan \& Kumar, 2004). Most of the factors that compose the CLV calculation can be positively influenced by the implementation of a relationship strategy. For instance, among the factors that make up CLV is the frequency of purchase, which is influenced by the firm's relationship strategy.

CRV aims to measure the financial impact of word of mouth and it is inspired by the metric proposed by Kumar et al. (2010). CRV is composed of the value derived from a customer's recommendations, based on the CLV calculation for each referred individual. The final CRV of a current customer is the sum of the CLVs of all the individuals referred by him or her. According to Rust, Lemon, and Zeithaml (2000), the effect of word of mouth is difficult to measure but is very important for marketing. Few studies have employed a financial measurement of word of mouth and referral behavior, and how word of mouth information can be used to guide customers consistently (Villanueva, Yoo, \& Hanssens, 2008).

Customers can be stimulated through active marketing actions, aiming to increase performance results and recommendations (Kumar et al., 2007). Working with marketing campaigns focused on incrementing one of the two indicators also helps to leverage results. Previous research has demonstrated how important it is to stay focused and take action to improve efficiency, even if the cost of running two campaigns is about the same as one. This is because many concurrent campaigns can lead to confusing information for the customer (Kumar et al., 2010). Another finding of the research shows how a customer can increase CRV even when consumption frequency and referral frequency are moderate (Kumar et al., 2010). Each additional purchase, even when less often, is an opportunity to share the experience with friends, leading to new purchases.

\section{Hypotheses}

The traditional relationship-marketing model, which evaluates consumers as isolated individuals and with no social interaction, is inappropriate. This model fails to account for the social effect, such as word of mouth and imitation, which influence future purchases (Hogan, Lemon, \& Libai, 2004). To maximize firm profitability, customers have to be managed by jointly considering the customer performance and the recommendation constructs (Kumar et al., 2010). Previous studies have shown the importance of CLV (Berger \& Schwartz, 2011) and CRV (Persson \& Andreas, 2013), however not in an integrated analytical model. This gives rise to the need to assess the impact of CLV and CRV in a fully-integrated model.

Analyzing the two constructs in an integrated way is relevant because a customer's value lies in what the person buys, how he or she feels about the brand, and what he or she may say, which influences firm revenue and profits (Reichheld, 2003). By advancing the analysis of the relationship between CRV and CLV, we sought 
to reinforce the nonlinear relationship found in a previous study (Kumar, Petersen, \& Leone, 2007). Although it has not been explored much in the literature, the literature does suggest a potential nonlinear effect between the two constructs, prompting further studies in this direction (e.g., Kumar et al., 2010). The relationship between customer performance and recommendation may not be linear: low-performing customer profiles can lead to a high recommendation rate and high-performance customers can also display high referral activity. Low CLV customers may feel compelled to recommend to potential buyers as a way of rewarding and repaying the firm for what it does well. High CLV customers are natural advocates for their own volume of purchases and investments (Chang \& Ijose, 2016). These customers are solid and aspirational references of future investments of potential buyers. Thus, the first hypothesis is presented below:

\section{H1: There is a positive non-linear (U-shaped) effect of Customer Lifetime Value (CLV) on Customer Referral Value (CRV).}

The tendency to recommend a firm's products and/or services emerges as an important predictive variable for revenue growth. Previous studies have shown the impact of the number of "promoters", that is, customers with a greater potential for repurchases and who add the largest margins to a firm, on the firm's growth (Reichheld, 2003). On the other hand, customers that generate the most business with firms are not necessarily the ones with the highest recommendation intention (Kumar et al., 2007). Thus, the promoters indicated in referral surveys would not necessarily be the firm's best customers in terms of total return, including sales performance and sales generation, compared to those customers who were impacted by that particular customer's word of mouth.

A high recommendation rate actually presents diverse results for different industries. The relationship between recommendation and growth in monopolistic or near monopoly industries, where the consumer has few options, may be low in terms of the recommendation effect on firm results (Reichheld, 2003). In industries with low brand differentiation and low customer involvement, as is currently the case of the retirement plans segment in Brazil, the choice is often made through inertia (Hidalgo et al., 2008). In addition, some studies also indicate that more interesting products generate immediate recommendations, but the products that generate the most long-term recommendations are those that are more visible or have more publicity (Berger, Jonah, \& Schwartz, 2011). In our paper, for some of the characteristics that lead to a low recommendation movement (i.e., a product that is not attractive for short term and with low exposure), it is expected that there is a negative relationship between recommendation and firm revenue growth added by customer value (i.e., CLV). Because of this, the question arises about the real value of customers known as promoters. A negative relationship is expected between the recommendation intention and the actual customer value of those identified as promoters. , This gives rise to the following two hypotheses:

H2: Customer value (current business volume) negatively affects recommendation intention.

H3: Customer Lifetime Value (CLV) negatively affects recommendation intention.

\section{Method}

In order to test the hypotheses, we collected data by surveying customers of a financial firm that mainly offers retirement plan products. The sample was randomly selected from the records of all customers proportional to purchased plan type (PGBL, VGBL, or Traditional) and plan mode (Individual and Underage Investor), with a 5\% sampling error and a 95\% confidence level. Thus, this first selection had approximately 1,000 clients and their contacts were sent to an 
outsourced data collection firm that carried out phone call interviews, preserving anonymity and preventing interference from the financial firm. After removing incomplete responses, our data collection effort yielded 768 complete customer responses, equivalent to a $77 \%$ response rate. We removed responses with CRV and CLV values way above the boxplot upper limit (upper limit = 3 rd quartile $+1.5 \mathrm{x}$ interquartile range) to avoid distortions in the multiple regression analysis.

We followed three steps in the data collection procedure. First, the intention to recommend was measured for each customer, based on a question with a scale ranging from 0 to 10 . To test hypotheses 2 and 3, a sample of 553 customers who answered that they recommended and provided the score for recommendation intention was used. The other two data collection steps were used to test hypothesis 1 . In the second step, a consumer's recommendation behavior was mapped, using a specific question about effective recommendation (yes or no answer), in which 345 customers replied that they recommended the firm's product. Finally, in the third step the respondents who claimed to have recommended the product provided the full names of the people to whom the product was indicated. In this final stage, 109 customers gave 205 names of people who were impacted by their recommendations. In total, 153 full individual names who received a recommendation were elicited in this step, averaging 1.4 names per respondent customer. Then, we identified the referred names in the firm's records, so that we could calculate the CLV for each referred name and compute the 109 respondent customers' CRV.

\section{I CLV measurement}

The CLV measure was based on the basic principles of Customer Lifetime Value (Venkatesan \& Kumar, 2004) plus two additions. First, we developed a specific survival variable, aiming to capture the customer's tendency to continue buying from the firm. We sought to identify a survival probability of each customer for the next 24 months. Second, we used information on customer revenue only, simplifying the measurement with no bias. CLV thus captures customer performance effectively and it is an important indicator for assessing customer recommendation activity.

The survival model, the first addition to the CLV calculation procedure, accounts for the estimation of a customer's tendency to remain as a customer for the next 24 months. The survival model analyzes the historical behavior of customers and, as a result, identifies the main factors that affect their permanence or exit. The factors are replicated in the total customer database to identify behavioral profiles and the likelihood of each customer maintaining their retirement plan active in the next 24-month period. For its construction, the model took into consideration: (1) an analysis of the past behavior of the active plans with more than 6 months at the end of the year of data collection, and (2) withdrawal behavior followed by cancellation of a plan in the next year.

The financial model aims to identify the revenue tendency for each individual in relation to any product in the firm. To simplify and adapt the CLV measure to the typical industry customer profile, the financial model for the CLV was estimated by only taking into account the revenue generator factors, for instance, frequency and value of contribution to the plan, withdrawals made in the period studied, accumulated balance in the retirement plan (i.e., inflows and outflows of resources and profitability obtained in the period), and purchases of additional benefits to the retirement plan. Such additional benefits may include protection benefits (life insurance and death pension, among others). The type(s) of investment fund(s) chosen by the customer, which can be fixed income, public or private securities, or mixed, were also identified. The assumptions, methodology, formulas, and validations of the survival and financial models are available upon request. 
Finally, the CLV includes the cross revenue collected for each customer, multiplied by his or her probability of surviving as the firm's customer:

$$
\mathrm{CLV}_{i}=\mathrm{S}_{i}(\mathrm{t}) \times \text { Revenue }
$$

where, $i$ denotes the $i$-th customer, $S(\mathrm{t})$ is the survival function in month $t$, and Revenue is the expected revenue from the customer's retirement plans for a maximum period of 24 months.

\subsection{CRV measurement}

Measuring CRV is more complex than measuring CLV, which may in part explain its low level of use by firms. However, it is important to use CRV to address the gap in the financial measurement of word of mouth. Our procedure for calculating CRV makes additions to simplify the original measure proposed by Kumar et al. (2010). This offers the possibility of firms in different industries employing this measure, especially those in service industries. In the survey questionnaire we identified the respondent customers who gave the complete names of individuals to whom they recommended the product and purchased plans. Subsequently, these names were identified in the firm's customer records. Based on an identification of those referred who actually acquired plans, it was possible to develop the measure to estimate the CRV of the customer who referred. In this case, the CRV was calculated as the sum of the CLVs of the referrals identified for the $i$-th customer, that is:

$$
\mathrm{CRV}_{i}=\sum_{j=1}^{m} \mathrm{CLV}_{-} \text {referral }_{j}
$$

At the end of this process, it was possible to differentiate recommendation intention, represented by the recommendation question with a score ranging from 0 and 10 , and the actual recommendation behavior, represented by CRV. Table 2 displays the variables used in our study.

Table 2

\section{Description of Variables}

\begin{tabular}{ll}
\hline Variable & Description \\
\hline CRV & Customer Referral Value (CRV), calculated for each respondent customer with valid referral names (Logarithm) \\
\hline Recommendation & Score given for the recommendation question (0-10) (Standardized) \\
\hline CLV & Customer Lifetime Value (CLV), calculated for each customer (Logarithm) \\
\hline Plan balance & Value of the accumulated reserve balance in the plan (in \$) (Logarithm) \\
\hline Satisfaction & Score given for the satisfaction question (0-10) (Standardized) \\
\hline Age & Customer age (in years) (Standardized) \\
\hline Gender & Gender of the customer (Female 0 and Male 1) \\
\hline Potential & Customer potential based on the segmentation strategy. Three classes: (3) AB, (2) C, and (1) DE \\
\hline Marital status & Marital status of the customer (Married 1 and Single 0) \\
\hline Region & GDP per capita of national regions \\
\hline Graduate & Customer education (Graduate 1 and Others 0) \\
\hline Plan type & Type of customer plan (VGBL 1 and PGBL or Traditional 0) \\
\hline Tax option & Tax option chosen by the customer, (Regressive 1 and Progressive or Traditional 0) \\
\hline Underage & Pension plan ownership for those underage (No 0 and 1 Yes) \\
\hline Tenure & Since first product purchase (in months) (Standardized) \\
\hline Recency & Time since the last contribution to the plan (in months) (Standardized) \\
\hline
\end{tabular}


Table 3 presents the descriptive measures and the correlations between the numerical variables used in the study. It is noted that the dispersion of the CRV, CLV, and balance of the plans is very high, as expected, so a logarithmic transformation was used to stabilize the variance of these variables, as described in Table 2. It is also observed that the average recommendation and satisfaction is high for the customers. Evaluating the correlations between the explanatory and control variables, there is only one strong correlation between CLV and balance $(r=0.811)$, but this is expected and is not considered high enough, according to Gujarati and Porter (2011), to lead to problems of multicollinearity in the regression model.

Table 3

\section{Descriptive Measures and Correlations between Numerical Variables}

\begin{tabular}{lcccccccc}
\hline Variable & $(1)$ & $(2)$ & $(3)$ & $(4)$ & $(5)$ & (6) & (7) & (8) \\
\hline CRV (1) & 1 & & & & & & & \\
Recommendation (2) & 0.051 & 1 & & & & & & \\
CLV (3) & 0.016 & -0.036 & 1 & & & & & \\
Balance (4) & 0.008 & -0.040 & 0.811 & 1 & & & & \\
Satisfaction (5) & 0.051 & 0.696 & -0.054 & -0.038 & 1 & & & \\
Age (6) & -0.008 & -0.042 & 0.296 & 0.368 & -0.010 & 1 & & \\
Time (7) & 0.065 & -0.081 & 0.050 & 0.061 & -0.072 & 0.059 & 1 & \\
Recency (8) & 0.032 & -0.035 & 0.024 & 0.045 & -0.009 & 0.089 & -0.016 & 1 \\
\hline Mean & 151.21 & 8.20 & 2139.46 & 54812.84 & 7.94 & 47.64 & 82.83 & 10.69 \\
Standard deviation & 1690.18 & 2.47 & 4787.09 & 133653.94 & 2.00 & 13.49 & 59.17 & 53.66 \\
\hline
\end{tabular}

\section{Results}

The final database included 109 customers to evaluate $\mathrm{H} 1$ and 553 respondents to evaluate $\mathrm{H} 2$ and $\mathrm{H} 3$, as explained in the previous section. The hypotheses were tested using ordinary least square regressions estimated using Stata software (15). A residual analysis was performed to verify the validity of the assumptions of the regression model, especially for error homoskedasticity (White test) and error normality (JarqueBera test). CRV models 1-3 did not present error normality; however, the sample size was considered large enough $(n=109)$ for the results to be robust. Also, the assumption of error homoskedasticity failed, so all standard errors presented are heteroskedasticity-robust. Finally, all the models report standardized coefficients, enabling comparison of the variables' effect.

Table 4 reports the regression models (1-3) to evaluate the impact of CLV on CRV. The complete model (Model 1) achieves good explanatory power $\left(\mathrm{R}_{\text {adj }}^{2}: 0.64\right)$. The effect of IDC $^{2}$ on CRV is positive and presents statistical significance, corroborating with hypothesis 1 , which predicts the existence of a non-linear, U-shaped relationship ( $\beta=0.05 ; p<0.05)$. In addition, a negative linear relationship between recommendation and satisfaction scores is also observed, showing that not always the highest scores attributed to these two items represent a greater number of effective indications for the firm.

In order to evaluate the robustness of the results, we estimated two competing models with constraints, by removing the statistically irrelevant variables (Models 2 and 3). These models further confirm the positive non-linear effect of CLV on CRV. The estimated models demonstrate that there are other variables that affect CRV. There is a positive influence of the male gender, the potential variable for higher classes, tenure, and recency. In addition to the satisfaction and recommendation scores, there is also a negative effect of customers with underage plans. 
Table 4

Results for Hypothesis 1

\begin{tabular}{|c|c|c|c|c|}
\hline \multirow[t]{2}{*}{ Variables } & \multirow[t]{2}{*}{ Hypothesis } & \multicolumn{3}{|c|}{$\begin{array}{c}\text { CRV } \\
\text { (Customer Referral Value) } \\
\end{array}$} \\
\hline & & Model 1 & Model 2 & Model 3 \\
\hline \multicolumn{5}{|l|}{ Independent Variables } \\
\hline Customer Lifetime Value (CLV) & & $-.37(-2.46)^{* *}$ & $-.39(-2.95)^{* * *}$ & $-.35(-2.68) * * *$ \\
\hline $\mathrm{CLV}^{2}$ & $\mathrm{H}_{1}$ & $.05(2.50)^{* *}$ & $.05(3.04)^{* * *}$ & $.04(2.76)^{* * *}$ \\
\hline \multicolumn{5}{|l|}{ Control Variables } \\
\hline Recommendation & & $-.66(-2.39) * *$ & $-.69(-2.61)^{* *}$ & $-.73(-2.77)^{* * *}$ \\
\hline Satisfaction & & $-.57(-3.73)^{* * *}$ & $-.55(-3.73)^{* * *}$ & $-.54(-3.65)^{* * *}$ \\
\hline Age & & $-.21(-1.76)^{*}$ & $-.17(-1.57)$ & \\
\hline Gender & & $1.06(6.07)^{* * *}$ & $1.08(6.29)^{* * *}$ & $1.12(6.58)^{* * *}$ \\
\hline Potential & & $.31(2.61)^{* *}$ & $.30(2.66)^{* * *}$ & $.23(2.20)^{* *}$ \\
\hline Marital Status & & $-.38(-1.91)^{*}$ & $-.36(-1.87)^{*}$ & $-.47(-2.54) * *$ \\
\hline Region & & $-.12(-2.47) * *$ & $-.12(-2.60) * *$ & $-.12(-2.71) * * *$ \\
\hline Graduate & & $-.05(-.25)$ & & \\
\hline Plan Type & & $.49(2.28)^{* *}$ & $.49(2.33)^{* *}$ & $.46(2.22)^{* *}$ \\
\hline Tax Option & & $-.14(-.76)$ & & \\
\hline Underage & & $-.87(-3.33)^{* * *}$ & $-.95(-4.86)^{* * *}$ & $-.96(-4.86)^{* * *}$ \\
\hline Tenure & & $.23(2.02)^{* *}$ & $.25(2.50)^{* *}$ & $.25(2.53)^{* *}$ \\
\hline Recency & & $.57(2.31) * *$ & $.55(2.29) * *$ & $.46(1.96)^{*}$ \\
\hline Plan Balance & & $.22(.62)$ & & \\
\hline Constant & & $5.75(12.42)^{* * *}$ & $5.66(13.70) * * *$ & $5.88(15.04)^{* * *}$ \\
\hline $\mathrm{R}^{2}$ & & 0.69 & 0.69 & 0.68 \\
\hline Adjusted $\mathrm{R}^{2}$ & & 0.64 & 0.65 & 0.64 \\
\hline F-statistic & & $12.06 * * *$ & $16.16 * * *$ & $17.05 * * *$ \\
\hline Observations & & 109 & 109 & 109 \\
\hline
\end{tabular}

Note: The table reports the coefficients, $t$-values in parentheses.

$* \mathrm{p}<.10 * * \mathrm{p}<.05 ; * * \mathrm{p}<.01$.

Hypotheses 2 and 3 were tested using ordinary least square regression for the sample containing 553 observations. The objective was to identify the relationship between recommendation intention, measured on a scale ranging from 0 to 10 , and the independent variables CLV and balance of plans. Models 6 and 7 in Table 5 show the negative linear relationship between CLV and recommendation $(\beta=-0.01, \mathrm{p}<0.05$ and $\beta=$ -0.03, p <0.10), which is in line with Hypothesis 3. Those customers with greater revenue volume and potential, measured by CRV, are not always 
the ones who promote the brand. Hypothesis 2 was not supported, as the effect of plan balance on recommendation is not significant, indicating that regardless of the customer business volume, the recommendation intention is on average the same.

Table 5

\section{Results for Hypothesis 2 and 3}

\begin{tabular}{|c|c|c|c|c|c|}
\hline \multirow{2}{*}{ Variables } & \multirow{2}{*}{ Hypotheses } & \multicolumn{4}{|c|}{ Recommendation } \\
\hline & & Model 4 & Model 5 & Model 6 & Model 7 \\
\hline \multicolumn{6}{|l|}{ Independent Variables } \\
\hline Plan Balance & $\mathrm{H}_{2}$ & $-.00(-.03)$ & $-.00(-.02)$ & $-.01(-.15)$ & $-.03(-.65)$ \\
\hline Customer Lifetime Value (CLV) & $\mathrm{H}_{3}$ & $-.01(-.26)$ & $-.01(-.28)$ & $-.01(-2.21)^{* *}$ & $-.03(-1.72)^{*}$ \\
\hline $\mathrm{CLV}^{2}$ & & $-.00(-.25)$ & $-.00(-.23)$ & & \\
\hline \multicolumn{6}{|l|}{ Control Variables } \\
\hline Satisfaction & & $.29(13.09)^{* * *}$ & $.29(13.12)^{* * *}$ & $.29(13.21)^{* * *}$ & $.29(13.63)^{* * *}$ \\
\hline Age & & $.01(.54)$ & $.01(.55)$ & & \\
\hline Gender & & $-.07(-2.07)^{* *}$ & $-.07(-2.10)^{* *}$ & $-.07(-2.18)^{* *}$ & $-.07(-2.37)^{* *}$ \\
\hline Potential & & $-.04(-1.79)^{*}$ & $-.04(-1.80)^{*}$ & $-.04(-1.97)^{* *}$ & $-.04(-2.13)^{* *}$ \\
\hline Marital Status & & $.00(.02)$ & & & \\
\hline Graduate & & $-.07(-1.65)^{*}$ & $-.06(-1.64)$ & $-.06(-1.67)^{*}$ & \\
\hline PlanType & & $.08(2.05)^{* *}$ & $.08(2.07)^{* *}$ & $.08(2.00)^{* *}$ & $.06(1.83)^{*}$ \\
\hline Tax Option & & $-.03(-.90)$ & $-.03(-.90)$ & & \\
\hline Underage & & $-.01(-.02)$ & $.00(.13)$ & & \\
\hline Tenure & & $-.02(-1.17)$ & $-.02(-1.14)$ & & \\
\hline Recency & & $-.03(-1.80)^{*}$ & $-.03(-1.80)^{*}$ & $-.03(-1.86)^{*}$ & $-.02(-1.76)^{*}$ \\
\hline Constant & & $.50(8.04)^{* * *}$ & $.50(8.11)^{* * *}$ & $.50(8.51)^{* * *}$ & $.40(8.64)^{* * *}$ \\
\hline $\mathrm{R}^{2}$ & & 0.29 & 0.29 & 0.29 & 0.28 \\
\hline Adjusted $\mathrm{R}^{2}$ & & 0.27 & 0.27 & 0.27 & 0.27 \\
\hline F-statistic & & $14.23 * * *$ & $16.48 * * *$ & $21.41 * * *$ & $29.92 * * *$ \\
\hline Observations & & 553 & 553 & 553 & 553 \\
\hline
\end{tabular}

\section{Discussion and Implications}

\subsection{Non-linear effect of customer value on the recommendation index}

In this paper, we seek to expand the understanding of customer performance and customer referral. The results show the existence of a U-shaped effect of CLV on CRV. This finding contributes to existing research that suggests a nonlinear relationship between customer performance indicators (CLV) and recommendation (CRV) (Kumar et al. 2007). Our study also contributes to the body of literature on word of mouth, by showing that products and/or business segments with low perceived brand differentiation and low customer involvement, as in our sample of the Brazilian retirement plan firm, do not stimulate 
customers to search for information, nor do they create customer involvement with key attributes of the product. On the contrary, consumers are passive recipients of information (Hidalgo et al., 2008). Moreover, previous research lacks an analysis of the effective relationship between performance and recommendation in low involvement industries. Thus, we contribute to the marketing literature by showing a U-shaped relationship between CLV and word of mouth activity, represented by CRV.

Based on our results, we further investigated our sample by identifying three typical profiles of consumers who recommended (Figure 1). A cluster analysis was performed to split the customers by CRV and CLV (in logarithms) and then the remarkable customer characteristics in each of the bands were identified. Figure 1 displays the scatter plot for CLV and CRV as well as the non-linear trend line, with an $\mathrm{R}^{2}$ equal to 0.108. We used the hierarchical method, the Euclidian distance as a measure of dissimilarity, and the Ward method in the cluster analysis, using a dendrogram to choose the number of groups. Range I demonstrates the existence of low CLV and high CRV customers. This range is made up of customers with reduced volumes and low future potential, but with high recommendation power. It includes customers who deactivated their plans after the survey, i.e. clients with a low propensity to stay in the long term, but also with a good volume of indications. In accordance with its basic profile, this group of customers can be defined as "Catalysts", which despite having low revenue potential for the company (CLV), promote profitability through a consistent number of indications (CRV). Based on the result obtained through cluster analysis, it can be stated that in this group there is balance between the genders and potential segments. A significant portion of this group is represented by the retail segment. The group has higher average satisfaction and recommendation scores and greater proximity to large cities.

Range II mainly comprises customers with medium potential for revenue generation (CLV) and indications that do not generate the highest recommendation volumes (CRV). In accordance with its basic profile, we can define this group of customers as "Neutrals", which are those that do not add significantly high value through their plans (CLV) and do not have aggressive recommendation behavior (CRV). These customers rate average on satisfaction and recommendation scores, representing the intermediate group compared to the other groups. There is still a predominance of customers with low potential, with low education, and greater female gender participation. This group also has the largest share of plans for children (underage). Finally, Range III contemplates the niche of customers with higher CLV and with CRV that indicates a good level of recommendation. Thus, this group can be defined as "Stars", because there is a predominance of customers with high potential (high income), high schooling, a high male gender percentage, and a low percentage of underage plans. 


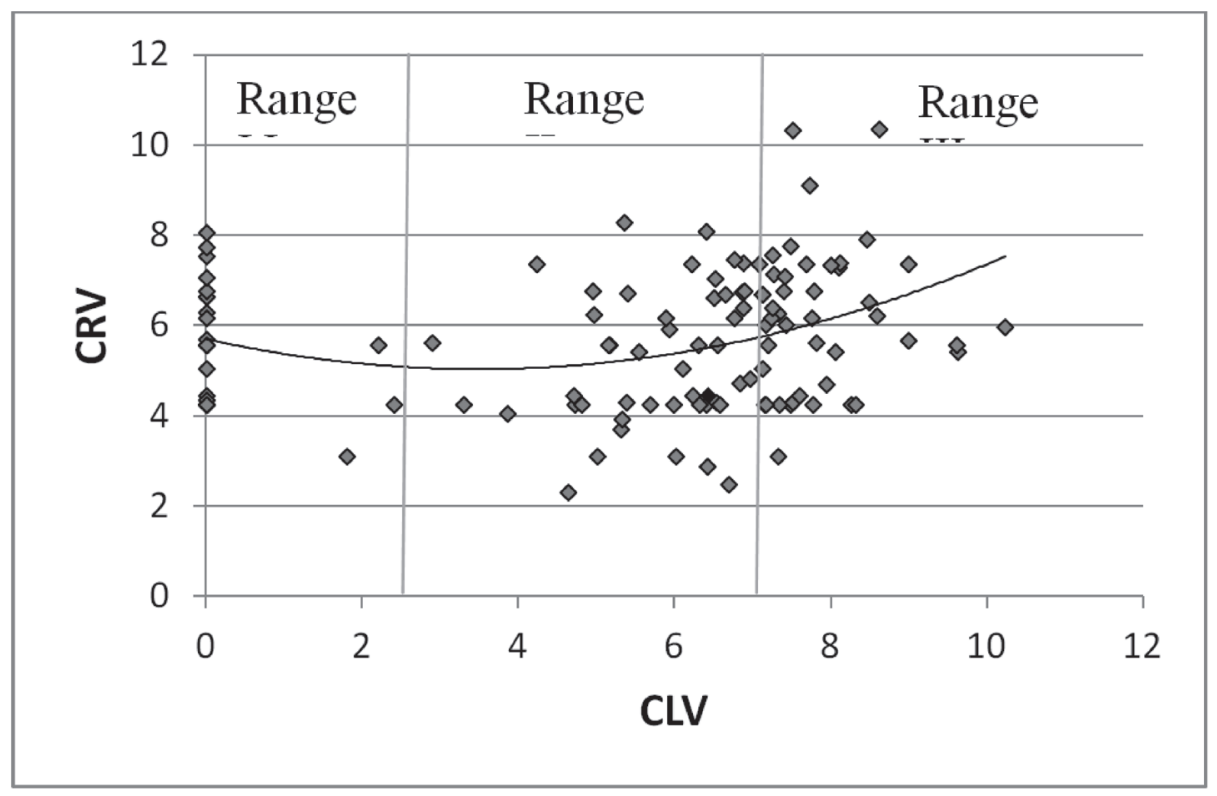

Figure 1. Scatter plot and trend curve of CRV as a function of CRV, both in logarithms.

The mass segment customers, mostly found in Ranges I and II, belong to the group that in the Brazilian market have been called the New Middle Class. They have a lower income and, consequently, lower purchasing power and average CLV. However, in this group, especially in Range I, there is potential for significant recommendation. There are opportunities for this segment associated with the strong expansion of the Brazilian middle class. According to a study carried out by Neri (2010), the new Brazilian middle class (i) already represents about $50 \%$ of the population, compared to $32.5 \%$ in 1992 , (ii) has an increasing income profile, and (iii) has a higher education level, with an average of 7.3 years in 2009, compared with 5.0 in 1992. As a result, they are highly prone to future consumption of savings and retirement plans. In addition, the expansion of this segment of the population's access to better quality healthcare accelerates the movement already identified in Brazil towards increased life expectancy and, consequently, the need for adequate personal, professional, and financial knowledge to meet this new reality. The ultimate challenge is to correctly understand the demands and needs of this public, which has different behavioral characteristics from the current customers of life and social security insurers, which have traditionally concentrated on higher income segments and the development of products and services adapted to their specific needs.

\subsection{Negative effect of customer value on recommendation intention}

The result obtained with respect to Hypothesis 2 demonstrates that the brand promoting customer identified in the recommendation surveys is not always the one that adds the greatest potential value to the firm, measured by CLV. This result contributes to existing word of mouth theory, including the seminal article about the concept of Net Promoter Score (NPS) (Reichheld, 2003). In Richheld's (2003) study, despite the fact that brand promoters are the customers with the highest value and repurchase potential, he emphasizes that no conclusive finding exists to support the effect of NPS on growth in industries with similar characteristics to our retirement plan firm. The industry has a monopolistic competition structure, where consumers have few options 
and there are strongly expanding markets. The complementary pension plan in Brazil presents these characteristics, with (i) accelerated growth, (ii) a high concentration in three large banks, (iii) strong bank manager influence in the product sales process, and (iv) a low level of comparison by consumers at the time of sale. These items generate questions regarding the validity of using the NPS methodology as an indicator of customer base performance and resource allocation and relationship marketing actions.

In addition, some researchers also question the results of the research on NPS, since a large amount of recommendation intention does not materialize. This fact can generate inconsistencies when using recommendation intention as a relationship marketing tool (Kumar et al., 2010). Keiningham, Cooil, Andreassen, and Aksoy (2007) also reinforced this argument, concluding that the correlation between NPS and company revenue growth is low. It is also worth mentioning that despite presenting sustainable growth in recent years and proven value for society in the long term, the investment product is not yet a mass product and has attributes that are considered complex. Furthermore, for many people these are not considered to be products that impact on other people's perceptions, because they are long-term products, with little tangible benefits in the short term. This perception differs from that of immediate consumption products or services, such as cars or hotels, where dissemination through word of mouth may be more intense.

\section{Final Considerations and Future Studies}

Based on our study, some recommendations for customer relationship managers could be followed if the manager's goal is to expand product sales through the word of mouth concept and track customer performance, with a focus not only on the value added by a customer individually (i.e., CLV), but also the value derived from the customer's referrals (i.e., CRV). First, companies can deepen their knowledge of customers with a strong propensity for effective recommendation, by mapping demographic, geographic, behavioral, and psychographic data. Second, it is possible to map, in the current customer database, individuals with a similar recommendation profile, in order to structure specific relationship actions that foster the expansion, in this consumer base, of the word of mouth process, and consequently of new business at a reduced acquisition cost in relation to the business originally generated in the banking network. Previous research has demonstrated the importance and effectiveness of actions aimed at specific customer niches with the clear goals of increasing performance or recommendation rates (Kumar et al., 2010). Third, there is also the possibility to identify consumers with this recommendation profile in the list of potential clients of the organization, with the initial aim of capturing new plans, and later applying a relationship marketing strategy that favors loyalty and expansion of the word of mouth process through these new customers.

While it addresses a significant number of customers, some limitations of this study give rise to opportunities for future studies. Carried out using the Brazilian retirement plan segment as a reference, this study reinforces the fragility of recommendation intention as an indicator that drives customer actions and increases revenue. One of the possible explanations that may have led to this result can be captured with the NPS in different industries (Reichheld, 2003). In industries with low marketing differentiation and low customer involvement (such as our focal firm), it can be seen that brand choices are made by inertia (Hidalgo et al., 2008). However, while executives often think that only consumer goods products are worthy of word of mouth, even less attractive products can get large amounts of word of mouth through advertising (Berger \& Schwartz, 2011). Therefore, future studies could expand the analysis to other industries with, for instance, a more fiercely competitive profile.

In this paper, we propose hypotheses and test them using a sample of consumers of 
a single company in a single industry of the Brazilian market. Although the sample includes a representative sample of the population, future studies could deepen the theme (i) by expanding the analysis to consumers of other companies in the same industry or (ii) by extending the investigation to other industries that already use the concept of recommendation as a way of measuring the performance of the customer base. Our paper considered a performance construct (CLV) and effective recommendation (CRV), which is adherent to the services segment and based on previous studies and formulations. Depending on the needs and objectives, other studies could seek a new adaptation based on the specific characteristics of the firm or industry under analysis. Finally, in order to simplify the data collection, this study did not consider whether the referred customers would buy the product without any recommendation. This factor is one of the items considered in the process of constructing the CRV measure (Kumar et al., 2010) and could be improved in future studies.

\section{References}

Brooks, R. C. (1957). 'Word of Mouth' Advertising in Selling New Products. Journal of Marketing, 22(2), 154-61.

Berger, Jonah; Schwartz, Eric M. (2011). What Drives Immediate and Ongoing Word of Mouth. Journal of Marketing Research, 48, 869-880.

Berger, P. D., \& Nars, N. I. (1998). Customer Lifetime Value: Marketing Models and Applications. Journal of Interactive Marketing, 12(1), 17-30.

Boulding, W., Staelin, R., Ehret, M., \& Johnston, W. J. (2005). A Customer Relationship Roadmap: What Is Known, Potential Pitfalls, and Where To Go. Journal of Marketing, 69(4), 155-166.

Chang, Chun-Wei, \& Olumide, I. (2016). Measuring Customer Lifetime Value: An Application in Credit Card Industry. Journal of Business Research, 1, 7-24
Dichter, E. (1966). How Word-of-Mouth Advertising Works. Harvard Business Review, 44, 147-166.

Dick, A. S., \& Basu, K. (1994). Customer Loyalty: Toward an Integrated Conceptual Framework. Journal of the Academy of Marketing Science, 22, 99-113.

Gujarati, D. N., \& Porter, D. C. (2011). Econometria Básica. Porto Alegre: AMGH Editora Ltda.

Hidalgo, P.; Manzur, E.; Olavarrieta, S.; Farías, P. (2008). Customer Retention and Price MatchingThe AFPs Case. Journal of Business Research, 61(6), 691-696.

Hogan, J. E., Lemon, K. N., \& Libai, B. (2004). Quantifying the Ripple: Word-of-Mouth and Advertising Effectiveness. Journal of Advertising Research, 44(3), 271-280.

Katz, E., \& Lazarsfeld, P. F. (1955). Personal Influence. New York: The Free Press.

Keiningham, T. L., Cooil, B., Andreassen, T. W., \& Aksoy, L. (2007). A Longitudinal Examination of Net Promoter and Firm Revenue Growth. Journal of Marketing, 71(3), 39-51.

Kotler, P., \& Armstrong, G. (1996). Principles of Marketing. Prentice Hall.

Kozinets, R. V., Valck, K., Wojnicki, A. C., \& Wilner, S. J. S. (2010). Networked Narratives: Understanding Word-of-Mouth Marketing in Online Communities. Journal of Marketing, 74(2), 71-89.

Kumar, V., Petersen, J. A., \& Leone, R. P. (2010). Driving Profitability by Encouraging Customer Referrals: Who, When, and How. Journal of Marketing, 74(5), 1-17.

Kumar, V., Petersen, J. A., \& Leone, R. P. (2007). How Valuable Is Word of Mouth? Harvard Business Review, 85(10), 139 - 146. 
Kumar, V.; Reinartz, W. (2016). Creating Enduring Customer Value. Journal of Marketing, 80, 36-68.

Neri, M. C. (2010). A Nova Classe Média: O Lado Brilhante dos Pobres. Rio de Janeiro: FGV/CPS.

Palmatier, R. W., Dant, R. P., Grewal, D., \& Evans, K. R. (2006). Factors Influencing the Effectiveness of Relationship Marketing: A MetaAnalysis. Journal of Marketing, 70(4), 136-153.

Persson, A. (2013). Profitable Customer Management: Reducing Costs by Influencing Customer Behaviour. European Journal of Marketing, 47, 857-876

Pfeifer, P. E., Haskins, M. E., \& Conroy, R. M. (2005) Customer lifetime value, customer profitability, and the treatment of acquisition spending. Journal of Managerial Issues, 17(1), 11-25.

Reichheld, F. F. (2003). The One Number You Need. Harvard Business Review, 81(12), 46-54.

Reinartz, W. J., \& Kumar, V. (2003). The Impact of Customer Relationship Characteristics on Profitable Lifetime Duration. Journal of Marketing, 67(1), 77-99.

Rust, R. T., Lemon, K. N., \& Zeithaml, V. A. (2004). Return on Marketing: Using Customer Equity to Focus Marketing Strategy. Journal of Marketing, 68(1), p. 109-127.
Ryu, G., \& Feick, L. (2007). A Penny for Your Thoughts: Referral Reward Programs and Referral Likelihood. Journal of Marketing, 71(1), p. 84-94.

Steiner, P. J. N., Schlemer, C. B., \& Pádua, F. P. Jr. (2005). Um estudo sobre o arrependimento de adolescentes proprietários de aparelho celular na cidade de Curitiba. Revista Eletrônica de Ciência Administrativa (RECADM), 4(2), 1-15.

Valenzuela, L., Torres, E., Hidalgo, P., \& Farías, P. (2014). Salesperson CLV Orientation's Effect on Performance. Journal of Business Research, 67(4), 550-557.

Venkatesan, R., \& Kumar, V. (2004). A Customer Lifetime Value Framework for Customer Selection and Resource Allocation Strategy. Journal of Marketing, 68(4), 106-125.

Villanueva, J., Yoo, S., \& Hanssens, D. M. (2008). The Impact of Marketing-Induced Versus Wordof-Mouth Customer Acquisition on Customer Equity Growth. Journal of Marketing Research, 45(1), 48-59.

Westbrook, R. A. (1987). Product/Consumption - Based Affective Responses and Postpurchase Processes. Journal of Marketing, 24(3), 258-270.

Zeithaml, V. A., Berry, L. L., \& Parasuraman, A. (1993). The Nature and Determinants of Customer Expectations of Service. Journal of the Academy of Marketing Science, 21(1), 1-12. 
About the Authors:

1. Sandro Bonfim da Costa, Professional Masters in Business Administration, Insper, Brazil.

E-mail: Sandro_bonfim@hotmail.com

ORCID

(iD) 0000-0002-2163-3427

2. Danny Pimentel Claro, PhD in Business, Wageningen University, Netherlands.

E-mail: dannypc@insper.edu.br

ORCID

iD 0000-0002-8387-0938

3. Adriana Bruscato Bortoluzzo, Doctor of Statistics, Universidade de São Paulo, Brazil.

E-mail: adrianab@insper.edu.br

ORCID

(D)0000-0003-2872-031X

\section{Contribution of each author:}

\begin{tabular}{|c|c|c|c|}
\hline Contribution & $\begin{array}{l}\text { Sandro Bonfim } \\
\text { da Costa }\end{array}$ & $\begin{array}{c}\text { Danny } \\
\text { Pimentel Claro }\end{array}$ & $\begin{array}{c}\text { Adriana Bruscato } \\
\text { Bortoluzzo }\end{array}$ \\
\hline 1. Definition of research problem & $\sqrt{ }$ & $\sqrt{ }$ & \\
\hline $\begin{array}{l}\text { 2. Development of hypotheses or research questions (empirical } \\
\text { studies) }\end{array}$ & $\sqrt{ }$ & $\sqrt{ }$ & \\
\hline 3. Development of theoretical propositions (theoretical Work) & $\sqrt{ }$ & $\sqrt{ }$ & \\
\hline 4. Theoretical foundation/ Literature review & $\sqrt{ }$ & $\sqrt{ }$ & \\
\hline 5. Definition of methodological procedures & $\sqrt{ }$ & $\sqrt{ }$ & $\sqrt{ }$ \\
\hline 6. Data collection & $\sqrt{ }$ & & \\
\hline 7. Statistical analysis & $\sqrt{ }$ & $\sqrt{ }$ & $\sqrt{ }$ \\
\hline 8. Analysis and interpretation of data & $\sqrt{ }$ & $\sqrt{ }$ & $\sqrt{ }$ \\
\hline 9. Critical revision of the manuscript & $\sqrt{ }$ & $\sqrt{ }$ & $\sqrt{ }$ \\
\hline 10. Manuscript Writing & $\sqrt{ }$ & $\sqrt{ }$ & $\sqrt{ }$ \\
\hline
\end{tabular}

